\title{
Damped Oscillations in Continuous Culture of Lactobacillus plantarum
}

\author{
By INN HEE LEE, *A. G. FREDRICKSON AND H. M. TSUCHIYA \\ Department of Chemical Engineering and Materials Science, \\ Department of Microbiology, University of Minnesota, \\ Minneapolis, Minnesota 55455, U.S.A.
}

(Received I8 September I974; revised 3 November 1975)

S UMMARY

Lactobacillus plantarum exhibited long-period damped oscillations when grown aerobically with glucose as the rate-limiting substrate. Hydrogen peroxide accumulated in the cultures and its concentration also exhibited damped oscillations. It is suggested that inhibition of growth by hydrogen peroxide is involved in the production of the damped oscillations of microbial population density.

\section{INTRODUCTION}

Oscillations of population density, biomass concentration, and environmental variables in pure microbial cultures have been reported.

Finn \& Wilson (I954) noted sustained oscillations of $\mathrm{pH}$, light extinction, and other variables in product-limited, continuous and batch cultures of Saccharomyces carlsbergensis in nutrient broth with $\mathrm{I} \%(\mathrm{w} / \mathrm{v})$ glucose; the period of these oscillations was of the order of $2 \mathrm{~h}$. Similar oscillations were reported by Maxon (1960) for growth of $S$. cerevisiae. Mateles \& Goldthwaite (1963), employing the same medium as Finn \& Wilson, observed no oscillations, sustained or damped, in $\mathrm{pH}$ or sugar concentration in product-limited continuous culture of $S$. carlsbergensis or Pseudomonas ovalis; they suggested that their results differed from those of Finn and Wilson because they obtained a continuous record of concentrations whereas Finn and Wilson only had data at discrete sampling times. However, Fiechter \& von Meyenburg (1968), using a continuous monitoring device in a study of gas exchange in continuous culture of $S$. cerevisiae, reported sustained oscillations of gas exchange rate with a period of about $2 \mathrm{~h}$.

Damped oscillatory responses of chemostat cultures to upset conditions were reported by Mor \& Fiechter (1968) for growth of $S$. cerevisiae (period about one day) and by Zines \& Rogers (I970) for growth of Klebsiella aerogenes (period < I h).

Oscillations observed have been ascribed to various causes: a time lag in the adjustment of yeast growth rate to a change in the $\mathrm{pH}$ of the surroundings (Finn \& Wilson, 1954); synchrony of reproduction by budding (Fiechter \& von Meyenburg, 1968); a time lag, modelled as a second order differential equation, in the adjustment of growth rate to changes in ethanol concentration (Zines \& Rogers, I970).

These reports of short period (of the order of hours or less) oscillations in pure cultures have been criticized by Sinclair et al. (I97I): 'Most [of these reports] can be explained as being the result of poor sampling techniques or bad practice in the application of $\mathrm{pH}$, foam, temperature or dissolved oxygen control.'

A number of models predict oscillations in continuous cultures of pure microbial 
populations. The inhibitor models of Ramkrishna, Fredrickson \& Tsuchiya (I967) predict damped oscillations under some conditions. If variable biomass composition is also allowed for, they will predict sustained oscillations under some conditions. Less complex models, such as the modification of the maintenance model of Ramkrishna et al. (I966) proposed by Megee et al. (1972), will also predict damped oscillations, as will the modification of Monod's model for endogenous metabolism proposed by Herbert (1958). These models suggest that genuine oscillations may occur if inhibition by metabolic products ('staling effects'), consumption of substrate for maintenance, or both, are significant effects in the culture being considered.

We report damped oscillations of long period (of the order of days) that occurred in continuous cultures of Lactobacillus plantarum with glucose as the limiting substrate. These effects only occurred with aerobic growth, never under anaerobic conditions.

\section{METHODS}

Organism. Lactobacillus plantarum ATCC2O2I 8 was used. It was carried in stock as a stab culture in medium containing $(\%, \mathrm{w} / \mathrm{v})$ : tryptone, 0.5 ; yeast extract, 2.5 ; glucose, $\mathrm{I} \cdot \mathrm{O}$; agar, $0.5 ; \mathrm{pH} 7 \cdot 0$ to $7 \cdot 2$. The stock cultures were incubated at $37^{\circ} \mathrm{C}$ for $48 \mathrm{~h}$ and then held in a refrigerator. They were transferred monthly.

Grow'th conditions. The chemostats and medium were those described by Lee, Fredrickson \& Tsuchiya (1974); the medium was at $\mathrm{pH} 6 \cdot 5$. Filtered air was sparged through the cultures. Redox potential was not measured. The nutrient supply for the continuous culture was regulated by stainless-steel hypodermic capillary wire. The hydraulic head of the medium reservoir forced the medium into the chemostat. The height of the reservoir was adjustable so that the holding time could be regulated; no pumps were needed. The chemostat was jacketed for temperature control at $27 \pm 0.5{ }^{\circ} \mathrm{C}$. To start up a chemostat, the stock culture was first transferred to $100 \mathrm{ml}$ of the medium in a $300 \mathrm{ml}$ Erlenmeyer flask. After incubation for $24 \mathrm{~h}$, this was inoculated into the chemostat which was run batchwise (with no feed) for $24 \mathrm{~h}$ and then run with feeding for a minimum of 5 days.

Analytical methods. Bacteria were counted with a model $\mathrm{Z}_{\mathbf{B}}$ Coulter counter (Coulter Electronics Inc., Hialeah, Florida, U.S.A.) with a $30 \mu \mathrm{m}$ aperture tube. Samples were diluted in a special saline as has been reported (Lee et al., I974).

Glucose was determined by the glucostat method (Worthington Manual, 1972). In samples where hydrogen peroxide was also present, it was first destroyed with catalase solution. Catalase was then destroyed by boiling the sample for $30 \mathrm{~s}$.

Hydrogen peroxide was determined immediately after filtration of the sample with a standard peroxidase method using dianisidine as the substrate (Worthington Manual, 1972).

Lactic acid was measured by a modified Barker \& Summerson (194I) method.

\section{RESULTS}

In the experiments (Fig. I), chemostat holding time (the reciprocal of the dilution rate) was varied, and glucose concentration, hydrogen peroxide concentration and cell density (i.e. bacterial count) were monitored. Glucose was fed at $0.85 \mathrm{~g} \mathrm{l}^{-1}$; the temperature was held at $27^{\circ} \mathrm{C}$ in all experiments.

When the holding time was $3.5 \mathrm{~h}$ (Fig. I $a$ ), glucose fell to a level below $10^{-3} \mathrm{~g} \mathrm{l}^{-1} \mathrm{im}$ mediately and stayed there throughout the experiment. The cell density initially fell, and after a brief undershoot settled down to a steady state level. The concentration of $\mathrm{H}_{2} \mathrm{O}_{2}$ sometimes showed an initial slight undershoot, but quickly settled down to a steady state level. 

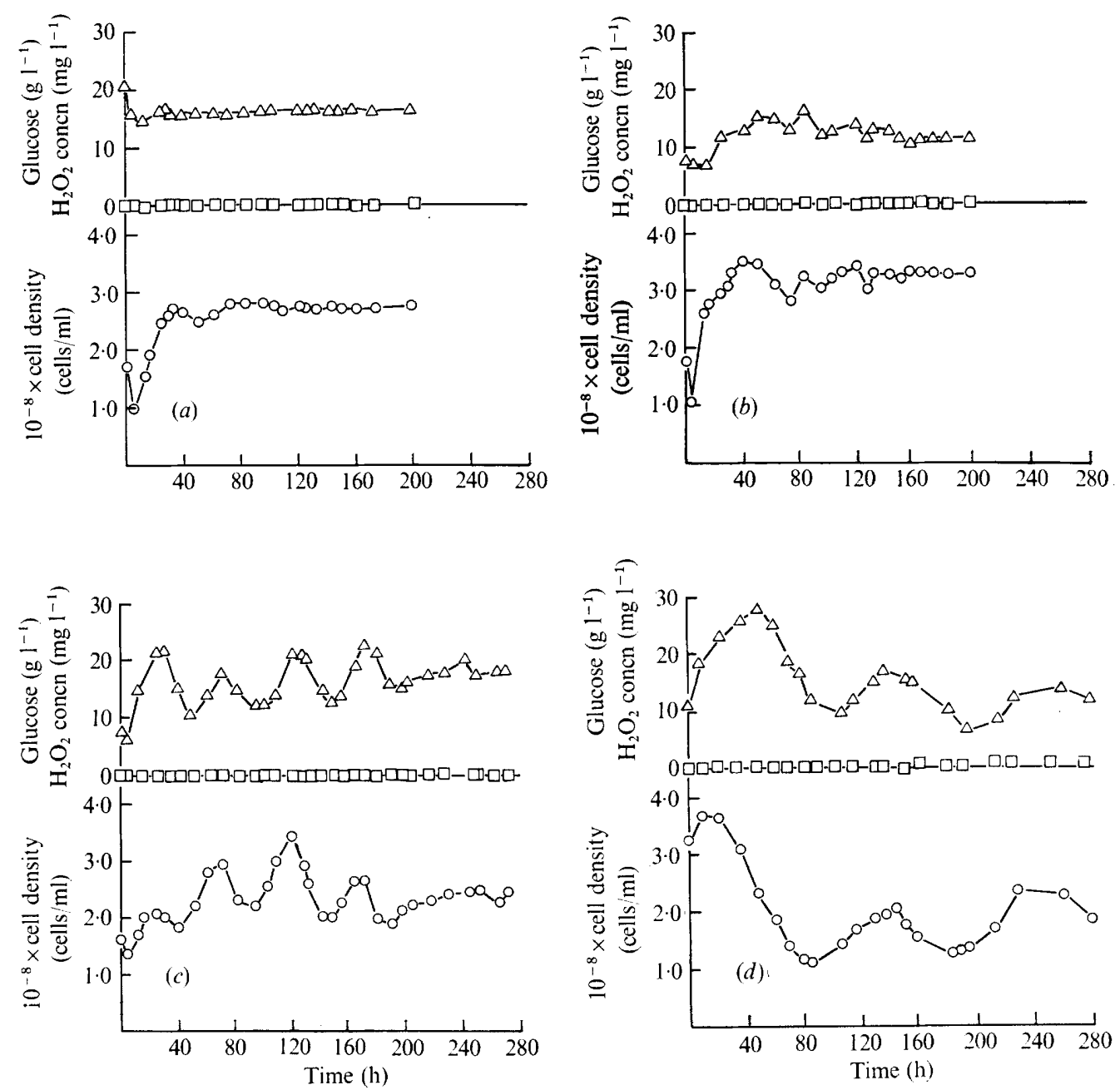

Fig. I. Transient data of aerobic, continuous culture of $L$. plantarum at holding times of (a) $3 \cdot 5 \mathrm{~h}$, (b) $7.0 \mathrm{~h},(c) 15.2 \mathrm{~h}$ and $(d) 38.0 \mathrm{~h}$. Sugar feed $0.85 \mathrm{~g} \mathrm{l}^{-1} ; \mathrm{pH} 6.5$; temperature $27^{\circ} \mathrm{C}$. $\triangle$, Hydrogen peroxide; $\square$, glucose $\left(<\mathrm{IO}^{-3} \mathrm{~g}^{-1}\right) ; 0$, cell density.

When the holding time was $7 \cdot 0 \mathrm{~h}$ (Fig. I $b$ ), glucose quickly fell to a level below $\mathrm{IO}^{-3} \mathrm{~g}^{-1}$. It is not altogether clear whether the cell density oscillated and then damped out. The concentration of $\mathrm{H}_{2} \mathrm{O}_{2}$ may also have shown damped oscillations. The toxicity of high concentrations of $\mathrm{H}_{2} \mathrm{O}_{2}$ to bacteria needs no comment.

Damped oscillations were apparent when the holding time was $15 \cdot 2 \mathrm{~h}$ (Fig. I $c$ ). Glucose fell to its usual level but definite oscillations in cell density could be seen. Similarly, damped oscillations were seen in the concentration of $\mathrm{H}_{2} \mathrm{O}_{2}$. As the cell density began to attain steady state, the hydrogen peroxide concentration also seemed to steady.

Finally, when the holding time was held at $38 \mathrm{~h}$ (Fig. I $d$ ), the glucose concentration steadied at less than $1 \mathrm{IO}^{-3} \mathrm{~g}^{-1}$ but the cell density and concentration of $\mathrm{H}_{2} \mathrm{O}_{2}$ underwent damped oscillations. The period and amplitude of oscillations generally increased as the holding time increased. 
Two chemostats were then set up in series, the effluent from one being the influent to the second. Glucose was fed at $\mathrm{I} \cdot 0 \mathrm{~g}^{-1}$, the $\mathrm{pH}$ was $6 \cdot 5$, and aerobic conditions prevailed. The holding time was $3.5 \mathrm{~h}$ in the first chemostat and $\mathrm{I} 4.5 \mathrm{~h}$ in the second. This was accomplished at the same feed rate by controlling the size of the chemostats. Glucose in the first chemostat fell quickly to its usual value. Lactic acid accumulated in these chemostat cultures at steady state conditions. The concentration of $\mathrm{H}_{2} \mathrm{O}_{2}$ steadied after initially oscillating slightly. The concentration of bacteria in both chemostats gradually stabilized. The holding time of the second chemostat should have been enough to have resulted in oscillations in organism numbers and the concentration of $\mathrm{H}_{2} \mathrm{O}_{2}$. However, essentially steady state conditions prevailed. Presumably the conditions in the first chemostat are controlling.

When the holding times were $12 \mathrm{~h}$ in the first chemostat and $6 \mathrm{~h}$ in the second, the glucose value quickly settled to its usual value but cell density, $\mathrm{H}_{2} \mathrm{O}_{2}$, and lactic acid began to oscillate.

Finally, an experiment was set up during which the holding time was increased from 3.8 to I $2.5 \mathrm{~h}$. When the holding time was $3.8 \mathrm{~h}$, glucose quickly settled to its usual concentration. Hydrogen peroxide concentration oscillated but did not exceed $20 \mathrm{mgl}^{-1}$. At this concentration the $\mathrm{H}_{2} \mathrm{O}_{2}$ is not sufficient to inhibit L. plantarum, so that no oscillations of organism numbers were found. When the holding time was raised to $\mathrm{I} 2.5 \mathrm{~h}$, however, oscillations developed in both the cell density and the concentration of $\mathrm{H}_{2} \mathrm{O}_{2}$.

\section{DISCUSSION}

The oscillatory phenomena reported here differ from most of those held to be spurious by Sinclair et al. (I97I): their period is of the order of days rather than hours. This is much longer than the period of the sole control device, a thermostat, which might have imposed external periodicity on the culture (no feed pumps, $\mathrm{pH}$ controllers, foam controllers, or dissolved oxygen controllers were used in the experiments). It is also much longer than the sampling period. These facts lead us to believe that the oscillatory phenomena reported here are not driven by external periodic processes but are a consequence of the imposition of an upset, such as a changed holding time, on the growth, metabolic and regulatory processes of the population.

The damped oscillations occur with $L$. plantarum under aerobic conditions, $\mathrm{pH}$ about 6.5 , at longer holding times, and at glucose levels of $\mathrm{r} \cdot 0 \mathrm{~g}{ }^{-1}$. They do not occur with short holding times.

The mechanism which produces the oscillations observed is not altogether clear. The observed production of $\mathrm{H}_{2} \mathrm{O}_{2}$, the well-known inhibitory effects of this compound on lactobacilli, and the observed oscillations in its concentration all suggest that it may play a major role in producing the oscillations. The damping out of $\mathrm{H}_{2} \mathrm{O}_{2}$ is a characteristic feature of this organism. Either the $\mathrm{H}_{2} \mathrm{O}_{2}$ damps out in concentration (it is unstable in the presence of organic matter), or the organisms adapt to it.

\section{REFERENCES}

Barker, S. B. \& Summerson, W. H. (I94I). The colorimetric determination of lactic acid in biological material. Journal of Biological Chemistry 138, 535-554.

Fiechter, A. \& von MeyenburG, K. (I968). Automatic analysis of gas exchange in microbial systems. Biotechnology and Bioengineering ro, 535-549.

FINN, R. K. \& WILSON, R. E. (I954). Population dynamics of a continuous propagator for microorganisms. Agricultural Food and Chemistry 2, 66-69. 
Herbert, D. (1958). Continuous culture of microorganisms; some theoretical aspects. In Continuous Cultivation of Microorganisms, a Symposium, pp. 45-53. Edited by I. Malek. Prague: Czechoslovak Academy of Sciences.

Lee, I. H., Fredrickson, A. G. \& Tsuchiya, H. M. (1974). Diauxic growth of Propionibacterium shermanii. Applied Microbiology 28, 83 I-835.

Mateles, R. I. \& Goldthwaite, R. W. (1963). Stability of product limited continuous culture systems. Biotechnology and Bioengineering 5, 49-52.

Maxon, W. D. (I960). Continuous fermentation. Advances in Applied Microbiology 2, 335-349.

Megee, R. D., III, Drake, J. F., Fredrickson, A. G. \& TsuchiYa, H. M. (I972). Studies in intermicrobial symbiosis. Saccharomyces cerevisiae and Lactobacillus casei. Canadian Journal of Microbiology 18, I733-I 742.

Mor, J. R. \& Fiechter, A. (I968). Continuous cultivation of Saccharomyces cerevisiae. II. Growth on ethanol under transient-state conditions. Biotechnology and Bioengineering 1o, 787-800.

Ramkrishna, D., Fredrickson, A. G. \& Tsuchiya, H. M. (I966). Dynamics of microbial propagation. Models considering endogenous metabolism. Journal of General and Applied Microbiology 12, 3 I I-327.

Ramkrishna, D., Fredrickson, A. G. \& Tsuchiya, H. M. (1967). Dynamics of microbial propagation. Models considering inhibitors and variable cell composition. Biotechnology and Bioengineering 9, 129170.

Sinclair, C. G., King, W. R., Ryder, D. N. \& Topiwala, H. H. (197I). Some difficulties in fitting dynamic models to experimental transient data in continuous culture. Biotechnology and Bioengineering $13,45 \mathrm{I}-$ 452.

Worthington Manual. Enzymes and Enzyme Reagents. (1972). New Jersey: Worthington Biochemical Corp.

ZINES, D. O. \& Rogers, P. L. (1970). The effect of ethanol on continuous culture stability. Biotechnology and Bioengineering $12,56 \mathrm{I}-575$. 